\title{
Los tipos de delitos contra la libertad sexual en el contexto social en la provincia de Tungurahua
}

Fecha de recepción: 2021-09-22 • Fecha de aceptación: 2021-12-14 • Fecha de publicación: 2022-01-10

Vicente Leonardo Pérez Yauli' Estudio Jurídico Acosta \& Asociados, Ecuador p.leonardo94@yahoo.es

https://orcid.org/0000-0003-1937-7820

Jorge Oswaldo Tamayo Viera² Tecnológico Superior Universitario España, Ecuador jorge.tamayo@iste.edu.ec https://orcid.org/0000-0002-2554-8684

Ibeth Aracelly Molina Arcos ${ }^{3}$ Tecnológico Superior Universitario España, Ecuador ibetha.molinaa@iste.edu.ec https://orcid.org/0000-0001-9650-1317

\section{Resumen}

En el presente artículo se analiza uno de los problemas considerado de significativa importancia desde la perspectiva social y jurídica, con implicaciones negativas para la sociedad, y en particular para la niñez y adolescencia, grupo de la población que por sus condiciones físicas y psicológicas son considerados como vulnerables, y por tanto, merecen especial y prioritaria atención del Estado y sus organismos: los delitos contra la libertad sexual, hechos que son consumados en contra de la voluntad, mediante la intimidación de la víctima o amenazas en contra de sus familiares; estos actos de naturaleza sexual provocan daños a nivel físico y psicológico en quien sufre la agresión y en sus allegados, se atenta contra la integridad y al pudor de las personas. En este orden, la explotación sexual de personas, prostitución forzada, pornografía, violencia sexual, acoso y abuso, violación, utilización de personas para exhibición pública con fines de naturaleza sexual, contacto 
con esta misma afinidad y oferta de servicios por medios electrónicos, trata de personas; son los delitos contra la libertad sexual más comunes. El objetivo planteado constituyó realizar un análisis de los principales delitos de este tipo y su incidencia en la población más vulnerable. En cuanto a los métodos empleados estos fueron: cualitativo, cuantitativo, descriptivo y bibliográfico, lo cual implicó la revisión de material documental, denuncias e informes de fiscalía relativos al objeto de estudio, la obtención de resultados y su interpretación mediante figuras con datos estadísticos. El periodo de estudio se centró en los años 2018 - 2021 en la Provincia de Tungurahua, Ecuador.

\title{
Palabras clave: libertad sexual, niñez, adolescencia, victima, delito
}

\begin{abstract}
This article analyzes one of the problems considered of significant importance from a social and legal perspective, with negative implications for society, and in particular for children and adolescents, a group of the population that due to their physical and psychological conditions are considered vulnerable, and therefore deserve special and priority attention from the State and its agencies: crimes against sexual freedom, acts that are committed against the victim's will, by intimidating the victim or threatening the victim's family members; these acts of a sexual nature cause physical and psychological damage to those who suffer the aggression and those close to them, and violate the integrity and modesty of persons. In this order, sexual exploitation of persons, forced prostitution, pornography, sexual violence, harassment and abuse, rape, use of persons for public exhibition for sexual purposes, contact with this same affinity and offer of services by electronic means, trafficking in persons; are the most common crimes against sexual freedom. The objective was to analyze the main crimes of this type and their incidence in the most vulnerable population. The methods used were: qualitative, quantitative, descriptive and bibliographic, which implied the review of documentary material, complaints and reports from the prosecutor's office related to the object of study, obtaining results and their interpretation by means of figures with statistical data. The study period focused on the years 2018 - 2021 in the Province of Tungurahua, Ecuador.
\end{abstract}




\section{Introducción}

A lo largo de la historia de la humanidad, los delitos contra la libertad sexual siempre han estado presentes en las distintas épocas y en las diferentes clases sociales, evidencia de aquello, en la esclavitud, el señor o patrón era quien tenía derechos sobre sus esclavos, quienes eran considerados objetos y con ellos hacia lo que, a bien tenia, de ahí que no resultase extraño que infringiera acciones indebidas en contra de sus esclavas. En la época de la conquista, la corona española instituyó como instrumento de dominación a indígenas y campesinos el derecho de pernada, el cual otorgaba a los hacendados o terratenientes de aquel periodo poder absoluto sobre la servidumbre, ocupaciones que generalmente fueron desempeñadas por mujeres aborígenes, quienes eran víctimas de abusos y violaciones por parte de su dueño. Este derecho no fue recogido en escrito alguno; sin embargo, por un lado, formó parte del derecho consuetudinario informal de la conquista, y por otro, fue acatado por la comunidad y tolerado por las autoridades (De Urabá, 2021).

Los delitos contra la libertad sexual, como se ha indicado, han existido desde tiempos remotos, así en los imperios de Grecia y Roma, estos se manifestaban bajo la figura de la pederastia en el caso de niños, y a través de relaciones homosexuales en el caso de los jóvenes, relaciones que hasta cierto punto se encontraban reguladas por la ley. En la edad media la sodomía constituyó la expresión de los delitos contra la libertad sexual, recibiendo la denominación de pecado delito, perseguido y castigado por la iglesia. En el siglo XIX estos delitos se circunscriben al círculo familiar trascendiendo esta esfera; pese a esto, las denuncias, aun cuando pudieron ser numerosas, los transgresores fueron pocos, debido a circunstancias de naturales jurídica y médica en detrimento de la protección de las víctimas (Martínez, 2015).

A nivel de Latinoamérica, los delitos de carácter sexual tienen índices elevados en relación a otras latitudes, esto se debe en gran medida a las concepciones de antaño en las que el hombre ejercía poder o pleno dominio, dando paso al abuso del poder, arbitrariedad actualmente conocido bajo la denominación de machismo; de otro lado, la falta de normas jurídicas que sancionen de forma adecuada al agresor, pero al mismo tiempo que guarden relación con el principio de proporcionalidad, es decir, exista relación entre la infracción y la pena establecida; adicional a estos factores los carentes niveles de orientación en el ámbito educativo, psicológico y sexual; ya que este tema, último en ciertos lugares, todavía se consideran cuestiones de contenido restringido o tabú.

No obstante, esta realidad, y dentro de este contexto en lberoamérica, se han desarrollado estudios tendientes a prevenir y reducir la ocurrencia de estos fenómenos, dirigidos fundamentalmente a niños, niñas, adolescentes, mujeres, hombres; quienes dada su condición resultan ser las personas más susceptibles de ser víctimas de los llamados delitos contra la libertad sexual, empleando para este cometido literatura y medios especializados que faciliten la comprensión de los temas abordados, buscando la inclusión de aquellos sectores menos favorecidos, localizados a las afueras de los centros urbanos, como las comunidades y pueblos indígenas (Tafur et al., 2019). 
Los actos de abuso, violencia y los delitos contra la libertad sexual se encuentran catalogados como experiencias devastadoras para las personas que las han experimentado, y por consecuencia, para sus familiares; los niños, niñas y adolescentes forman parte de los llamados grupos de atención prioritaria; es decir, por sus condiciones son los más vulnerables en la sociedad, por cuanto el espacio en el que se desenvuelven no les brinda la seguridad suficiente, ni la orientación, protección para prevenir y remediar estos hechos que marcaran su existencia (Ministerio de Educación, 2011).

Los delitos de carácter sexual se hacen manifiestos con mayor frecuencia en la sociedad y de forma particular en el contexto familiar; en la mayoría de los casos y de acuerdo a los reportes de denuncias, noticiarios; los agresores o victimarios no son personas alejadas al núcleo familiar, por el contrario, constituyen allegados a la víctima: padres, padrastros, tíos, hermanos, etc., quienes de manera astuta, con artimañas en casos contados, y; en su mayoría haciendo uso de la fuerza, coaccionan a su víctima a realizar actos contrarios a su voluntad.

En el Ecuador, actualmente existen leyes que tomando en consideración la norma constitucional han sido expedidas, precisamente con el propósito de tutelar o amparar a los sectores más vulnerables o débiles de la sociedad, en los cuales la ocurrencia de los delitos (Ernst, 2007) contra la libertad sexual tiene mayor incidencia; sin dejar de lado que en otras esferas sociales estos hechos también acaecen; sin embargo, pueden quedar en la impunidad al no ser de conocimiento público por la falta de denuncia, esto debido a la acción del perpetrador del delito, traducida en intimidación o ayuda económica a la víctima y sus familiares.

De acuerdo con los datos aportados por el Sistema de Protección de Víctimas y Testigos de la Fiscalía de Tungurahua, en la provincia, los delitos contra la libertad sexual se han incrementado en relación a datos de periodos anteriores; no obstante, a las medidas que se han adoptado para frenar estos delitos; el acoso sexual, estupro, abuso sexual y violación, constituyen los casos que con más frecuencia se denuncian, con menor incidencia las denuncias por pornografía; las principales víctimas son menores cuya edad está comprendida entre los siete y nueve años (La Hora, 2017).

Entre las normas legales que se han expedido y reformado por el legislativo, y que se ocupan de estos temas y de la protección las victimas a través del reconocimiento de sus derechos; se encuentran el Código Orgánico Integral Penal, Código Orgánico de la Niñez y Adolescencia, Código Orgánico de la Salud; su texto responde a las necesidad y exigencias de la colectividad, especialmente de los movimientos sociales de mujeres y niños (Ernest, 2020, p. 1).

Lo dicho guarda relación con el capítulo tercero de la Constitución de la República del Ecuador (Asamblea Nacional del Ecuador, 2008), respecto de los grupos de atención prioritaria y sus derechos; así lo establece el siguiente artículo:

Art. 35.- Las personas adultas mayores, niñas, niños y adolescentes, mujeres embarazadas, personas con discapacidad, personas privadas de libertad y quienes adolezcan de enfermedades catastróficas o de alta complejidad, recibirán atención prioritaria y especializada en los ámbitos público y privado. La misma atención prioritaria recibirán 
las personas en situación de riesgo, las víctimas de violencia doméstica y sexual, maltrato infantil, desastres naturales o antropogénicos. El Estado prestará especial protección a las personas en condición de doble vulnerabilidad.

De acuerdo al contenido de la norma constitucional, en particular al referir a los grupos de atención prioritaria y la relación con los delitos contra la libertad sexual, en estos no solo figuran como victimas mujeres independientemente de su condición física, psicológica, edad, preparación, etc.; también hombres caracterizados por su minoría de edad; un aspecto importante al referir a estos hechos es que cuando se habla de género, esta expresión es empleada para aludir a cualquier género de la especie humana, que resulte afectada por actos contrarios a su voluntad en su persona y sexualidad; de manera puntual describe a hombres y mujeres, entre ellos niños, niñas y adolescentes, sin descuidar claro está los altos índices de ocurrencia en mujeres mayores de edad, incluso de la tercera edad, y; en aquellas personas con discapacidad, sea esta física o mental, que dada su condición se consideran en situación de una doble vulnerabilidad (Estrella, 2019).

El actual Código Orgánico Integral Penal (Asamblea Nacional del Ecuador, 2021) incorpora cambios sustanciales en relación con su antecesor de 1938, de ahí que, dentro de su texto se encuentran establecidos cada uno de los delitos contra la libertad sexual; conceptualizándolos y facilitando la comprensión de los mismos; además, identifica el bien jurídico protegido que en este caso constituyen la integridad y libertad de las personas o víctimas (Ortiz, 2020).

En este sentido, los delitos contra la libertad sexual son conceptualizados de la siguiente forma, en consideración a lo establecido dentro de la estructura del Código Orgánico Integral Penal (2021):

- Trata de personas. Relativo a la captación, transporte, traslado de una o más personas dentro o fuera del país con fines de explotación.

- Explotación sexual de personas. Concerniente a la venta, préstamo, aprovechamiento o intercambio de personas para ejecutar uno o más actos de naturaleza sexual.

- Prostitución forzada. Referente a la obligación, exigencia, imposición contra voluntad de actos de naturaleza sexual.

- Pornografía con utilización de niñas, niños o adolescentes. Alusivo a las fotografías, filmes, grabaciones, producciones, transmisiones o edición de material visual, audiovisual, con representaciones visuales de desnudos o semidesnudos de niñas, niños o adolescentes en actitud sexual.

- Violencia sexual contra la mujer o miembros del núcleo familiar. Refiere a la imposición u obligación a mantener relaciones sexuales a la mujer o algún miembro del grupo familiar.

- Acoso sexual. Consiste en la solicitud de actos sexual, abusando de la situación de autoridad laboral, docente, religiosa o similar, etc.

- Estupro. Relativo a las relaciones sexuales de una persona mayor de 18 años con otra u otras mayores de 14 y menores de 18 años. 
- Distribución de material pornográfico. Referente a la difusión, venta o entrega de material pornográfico a niñas, niños o adolescente.

- Corrupción de niñas, niños y adolescentes. Concerniente a la incitación, conducción o permisión de niñas, niños o adolescente a prostíbulos o lugares en los que se exhibe pornografía.

- Abuso sexual. Consistente en la ejecución en contra de la voluntad de actos sexuales sin penetración o acceso carnal.

- Violación. Relacionado al acceso carnal, con introducción total o parcial del miembro viril, por vía oral, anal o vaginal; o, de objetos, dedos u órganos distintos al miembro viril.

- Utilización de personas para exhibición pública con fines de naturaleza sexual. Referido a exhibición forzosa del cuerpo total o parcial con fines de naturaleza sexual, en niños, niñas, adolescentes, discapacitados o personas mayores de 65 años.

- Contacto con finalidad sexual con menores de dieciocho años por medios electrónicos. Atinente a la utilización de medios electrónicos o telemáticos para concertar encuentros con personas mayores de 18 años, acompañados de actos orientados al acercamiento sexual o erótico.

- Oferta de servicios sexuales con menores de dieciocho años por medios electrónicos. Relacionado a la utilización de correos electrónicos, chats, mensajería instantánea, etc., para ofrecer servicios sexuales con menores de 18 años de edad.

Por su parte, el Código de la Niñez y Adolescencia establece desde su artículo primero la obligatoriedad del Estado, la sociedad y la familia de proporcionar la protección necesaria a niños, niñas y adolescentes, con el propósito de favorecer su desarrollo integral, en el marco del respeto absoluto a la libertad, dignidad y equidad; adicional a esto regula el conjunto de derechos que les es reconocidos conforme el principio de interés superior, y; como contrapeso a estos sus deberes u obligaciones, como también los medios indispensables para lograr su efectividad, garantía y protección.

De lo dicho, y con relación concreta al tema que concierne el Título IV del referido Código, regla la protección de niños, niñas y adolescentes ante los actos de maltrato, entendido este como toda acción u omisión que cause daño a la integridad o salud física, psicológica o sexual de la víctima; abuso sexual entendido como todo contacto físico de naturaleza sexual infringido con seducción, chantaje, intimidación, etc.; explotación sexual manifiesta en la prostitución y pornografía infantil, tráfico consistente en el traslado, sustracción o retención de la persona para actividades de prostitución, pornografía u otras actividades ilícitas; pérdida relativa a la ausencia del perjudicado sea esta voluntaria o no del hogar, centro educativo o cualquier lugar en el que deba permanecer (Asamblea Nacional del Ecuador, 2014).

En la sociedad actual, los delitos contra la libertad e intimidad sexual se producen con tanta frecuencia en contra de mujeres mayores y menores de edad, también de personas menores del sexo masculino; lo cual trae consigo consecuencias exteriorizadas en afecciones de por vida, no solo físicas, sino que también psicológicas. La ocurrencia de estos hechos, general conmoción o 
alarma en la sociedad, dado los elevados índices de incidencia, lo cuales no disminuyen pese a los constantes esfuerzos de grupos feministas dedicados a la defensa de los derechos de mujeres, niños, niñas y adolescentes, y; el endurecimiento de las sanciones para los infractores por parte de los órganos encargados de la administración de justicia (Mejía-Rodríguez et al., 2015).

\section{Metodología}

Para la realización de este estudio se aplicaron los métodos cualitativo, cuantitativo, descriptivo y bibliográfico, contrastando información relacionada a los delitos contra la libertad sexual más comunes y que presentan con mayor frecuencia en la provincia de Tungurahua, tomando como referencia definiciones y criterios de autores, del Código Orgánico Integral Penal (2021) y del Código de la Niñez y Adolescencia (2014). De igual forma se recogió información, material documental y estadísticas proporcionadas por el sistema integrado de actuaciones fiscales de la Fiscalía Provincial de Tungurahua en relación al número de denuncias registradas en el periodo comprendido entre los años 2018 - 2021, lo cual facilitó la obtención de resultados y su interpretación mediante figuras con datos estadísticos.

\section{Resultados}

A continuación, se presentan los siguientes resultados a raíz de la investigación realizada.

Tabla 1.

Tipos de delitos contra la libertad sexual

\begin{tabular}{ll}
\hline Artículo 91-92 & Trata de personas \\
\hline Artículo 100 & Explotación sexual de personas \\
\hline Artículo 101 & Prostitución forzada \\
\hline Artículo 103 & Pornografía con utilización de niñas, niños o adolescentes \\
\hline Artículo 158 & Violencia sexual contra la mujer o miembros del núcleo familiar \\
\hline Artículo 166 & Acoso sexual \\
\hline Artículo 170 & Abuso sexual \\
\hline Artículo 171 & Violación \\
\hline Artículo 172 & Utilización de personas para exhibición pública con fines de naturaleza sexual \\
\hline Artículo 173 & Contacto con finalidad sexual con menores de dieciocho años por medios electrónicos \\
\hline Artículo 174 & Oferta de servicios sexuales con menores de dieciocho años por medios electrónicos \\
\hline
\end{tabular}

Fuente: Fiscalía General del Estado (2021)

Los delitos contra la libertad sexual están contemplados en la legislación ecuatoriana a través de sus correspondientes artículos establecidos en el Código Orgánico Integral Penal (Tabla 1). Todos estos apartados buscan sancionar de forma ejemplar y enérgica cualquier acto que se produzca y que atente la dignidad y la honra de las personas. Entre éstos delitos tenemos los más comunes y que presentan altas tasas de registros como el acoso sexual, el abuso sexual, la violación. Actualmente han proliferado muchos delitos contra la libertad sexual a través de medios electrónicos. 
Tabla 2.

Personas involucradas en el cometimiento del delito sexual

\begin{tabular}{lc}
\hline \multicolumn{1}{c}{ Parentesco } & $\begin{array}{c}\text { Participación en el } \\
\text { cometimiento del delito } \\
\text { sexual }\end{array}$ \\
\hline Padrastros & \\
\hline Tíos & $60 \%$ \\
\hline Abuelos & \\
\hline Hermanos & \\
\hline Primos & $40 \%$ \\
\hline
\end{tabular}

Seis de cada diez delitos sexuales son cometidos por personas cercanas a las víctimas como padrastros, tíos, abuelos, hermanos, primos, lo que representa un sesenta por ciento de casos de delitos contra la libertad sexual a nivel nacional durante el año 2021 (El Universo, 2021). En el cuarenta por ciento restante están involucradas otras personas que pueden tener o no relación de parentesco con la persona victimada.

Tabla 3.

Porcentaje de mujeres que han vivido violencia sexual

\begin{tabular}{lcccc}
\hline Desagregación & $\begin{array}{c}\text { En el ámbito } \\
\text { educativo }\end{array}$ & $\begin{array}{c}\text { En el ámbito } \\
\text { Laboral }\end{array}$ & $\begin{array}{c}\text { En el ámbito } \\
\text { Social }\end{array}$ & $\begin{array}{c}\text { En el ámbito } \\
\text { Familiar }\end{array}$ \\
\hline Nacional & $7,0 \%$ & $6,8 \%$ & $23,5 \%$ & $3,7 \%$ \\
\hline Urbana & $7,7 \%$ & $7,8 \%$ & $27,3 \%$ & $3,9 \%$ \\
\hline Rural & $5,2 \%$ & $3,8 \%$ & $14,1 \%$ & $3,1 \%$ \\
\hline Sierra & $8,4 \%$ & $8,1 \%$ & $25,3 \%$ & $3,8 \%$ \\
\hline Costa & $5,8 \%$ & $5,9 \%$ & $22,5 \%$ & $3,4 \%$ \\
\hline Amazonía & $6,3 \%$ & $5,9 \%$ & $16,8 \%$ & $5,8 \%$ \\
\hline Insular & $3,8 \%$ & $3,8 \%$ & $11,3 \%$ & $3,2 \%$ \\
\hline Tungurahua & $7,6 \%$ & $4,7 \%$ & $19,5 \%$ & $2,1 \%$ \\
\hline
\end{tabular}

Fuente: Instituto Nacional de Estadística y Censos (2019)

En el Ecuador, la violencia sexual que han vivido las mujeres se manifiesta en el ámbito educativo, laboral, social y familiar, como se muestra en la Tabla 3. En el año 2019 se registran considerables porcentajes de violencia sexual contra la mujer en los ámbitos educativo y laboral. De igual manera, el sector urbano de la región sierra presenta un mayor porcentaje de casos de violencia sexual que la costa. En Tungurahua se contabiliza un alto porcentaje de mujeres que han vivido violencia sexual en el ámbito educativo con un $7,6 \%$. 
Figura 1.

Trata de personas

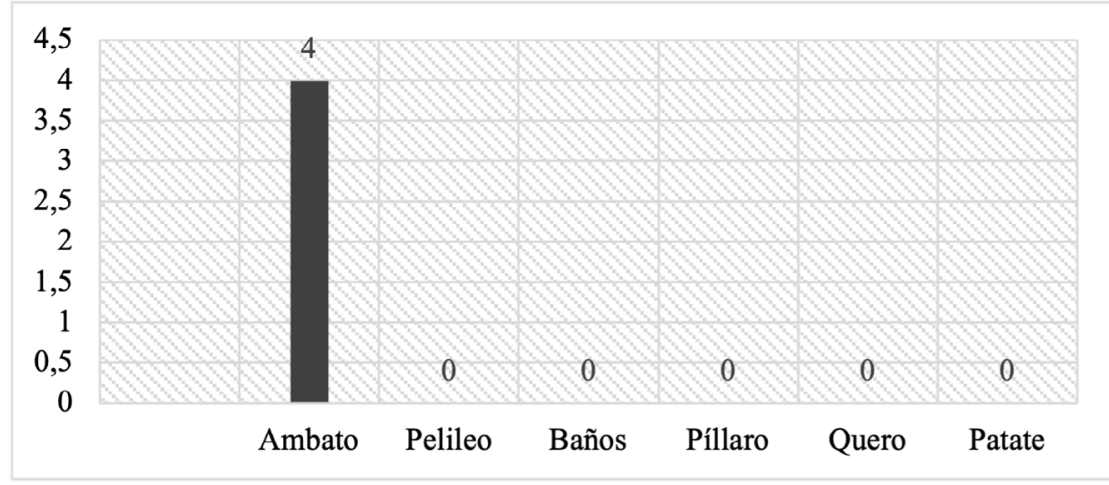

Fuente: Fiscalía General del Estado

El cantón Ambato constituye el centro de atención de toda la provincia de Tungurahua, porque es donde se cometen la mayor cantidad de delitos en contra de la libertad sexual, como se observa en la Figura 1. Se registran cuatro casos de delitos de trata de personas contemplado en los artículos 91 y 92 del Código Orgánico Integral Penal. Básicamente se ha registrado un caso por año durante el período de estudio comprendido desde el año 2018 al 2021 respectivamente.

\section{Figura 2.}

Explotación sexual de personas

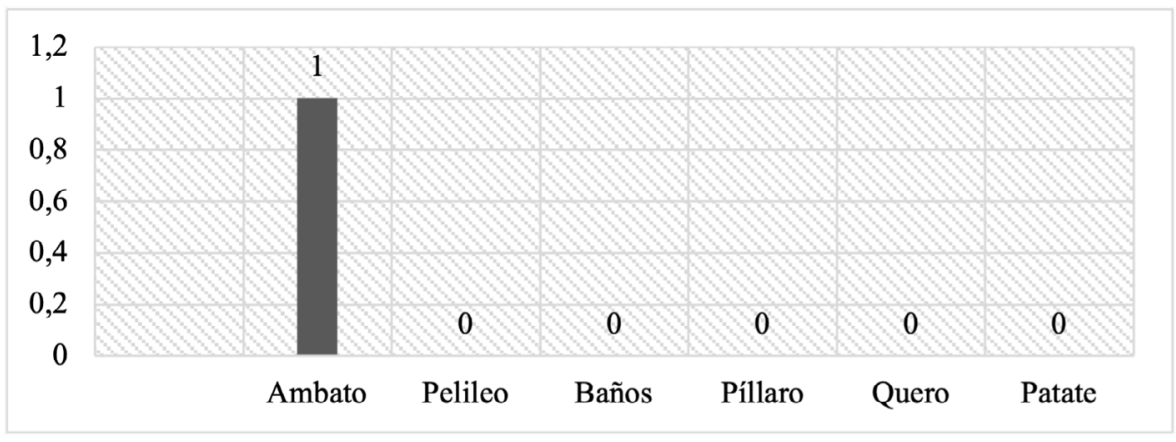

Fuente: Fiscalía General del Estado (2021)

En el período comprendido entre el año 2018 al 2021 se contabiliza en el cantón Ambato de la provincia de Tungurahua, un delito de explotación sexual de personas, de acuerdo al estado procesal y registrado en el archivo aceptado de la Fiscalía General del Estado (Figura 2). En el resto de cantones no se ha producido ningún caso relacionado con este tipo de delito de conformidad a lo estipulado en el artículo 100 del Código Orgánico Integral Penal. 
Figura 3.

Prostitución Forzada

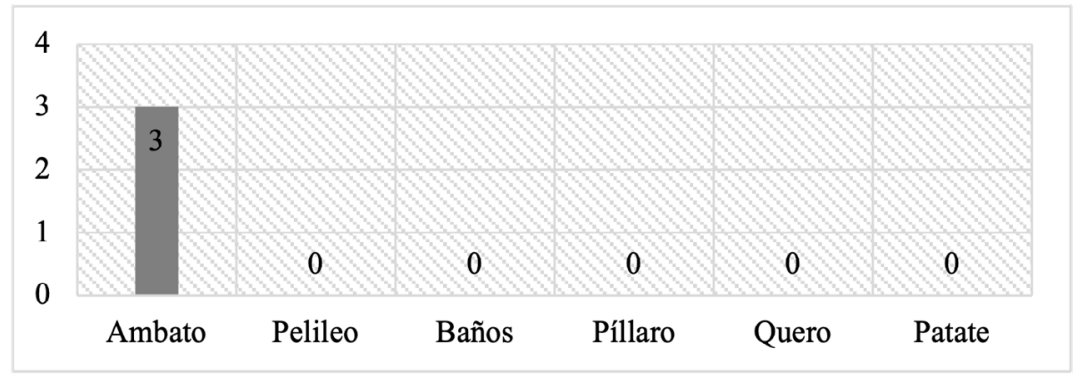

Fuente: Fiscalía General del Estado (2021)

De acuerdo con la Figura 3, se registran tres delitos de prostitución forzada en el año 2018, 2019 y 2021 respectivamente en el cantón Ambato, de los cuales dos casos corresponden a investigación previa y un caso está en el archivo aceptado de acuerdo al estado procesal del sistema integrado de actuaciones fiscales. No existe ningún caso relacionado con este tipo de delito en los cantones de Pelileo, Baños, Píllaro, Quero y Patate.

\section{Figura 4.}

Pornografía con utilización de niñas, niños o adolescentes

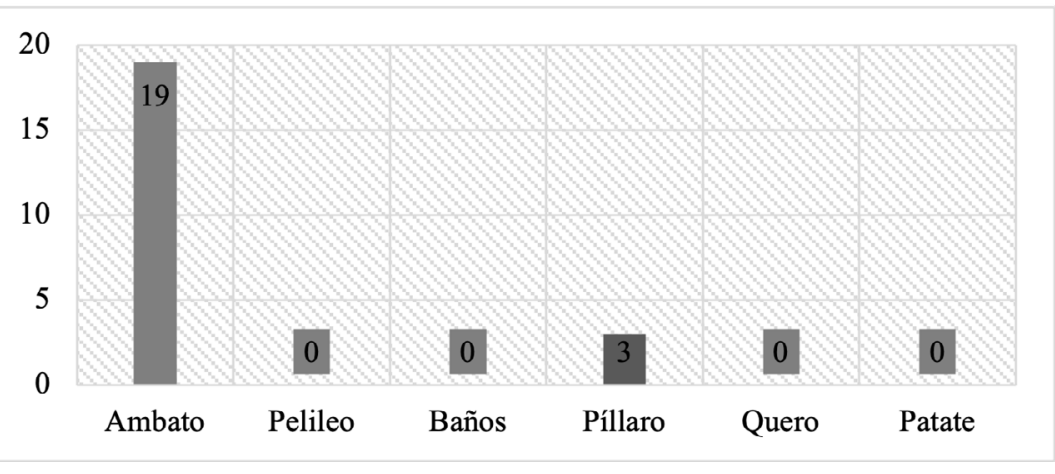

Fuente: Fiscalía General del Estado (2021)

Como se observa en la Figura 4, el cantón Ambato registra la mayor tasa de delitos de pornografía con utilización de niñas, niños o adolescentes con diez y nueve casos, seguido del cantón Santiago de Píllaro con tres delitos. En el año 2018 se contabilizan ocho delitos, en el 2019 se presentan cinco casos. En el 2020 se incrementa a siete delitos. Al primero de agosto de 2021 existen 2 casos. En el resto de cantones de la provincia de Tungurahua no se han producido delitos de ésta índole. 
Figura 5.

Violencia sexual contra la mujer o miembros del núcleo familiar

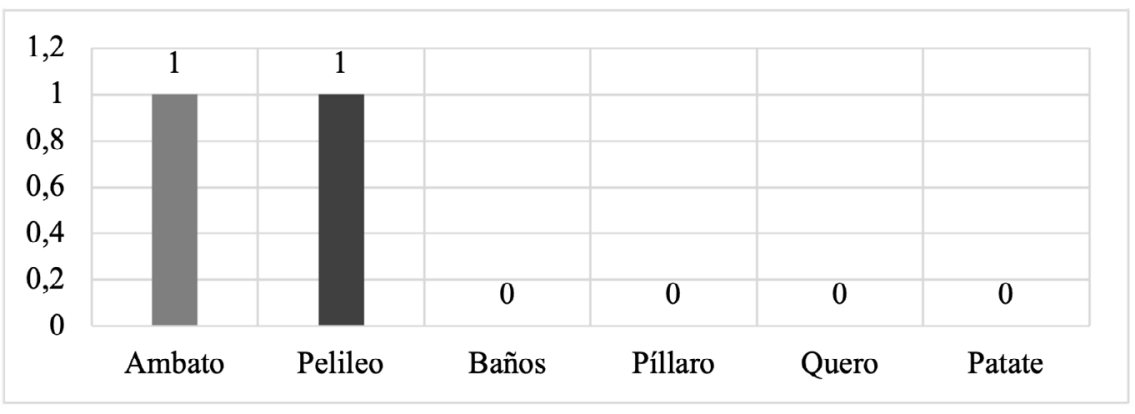

Fuente: Fiscalía General del Estado (2021)

En relación a delitos de violencia sexual contra la mujer o miembros del núcleo familiar se registran dos casos (Figura 5). Los cantones de Ambato y San Pedro de Pelileo presentan un caso respectivamente en los años 2019 y 2020. De acuerdo al estado procesal emitido por el sistema integrado de actuaciones fiscales, estos delitos se encuentran en investigación previa.

Figura 6.

Acoso sexual

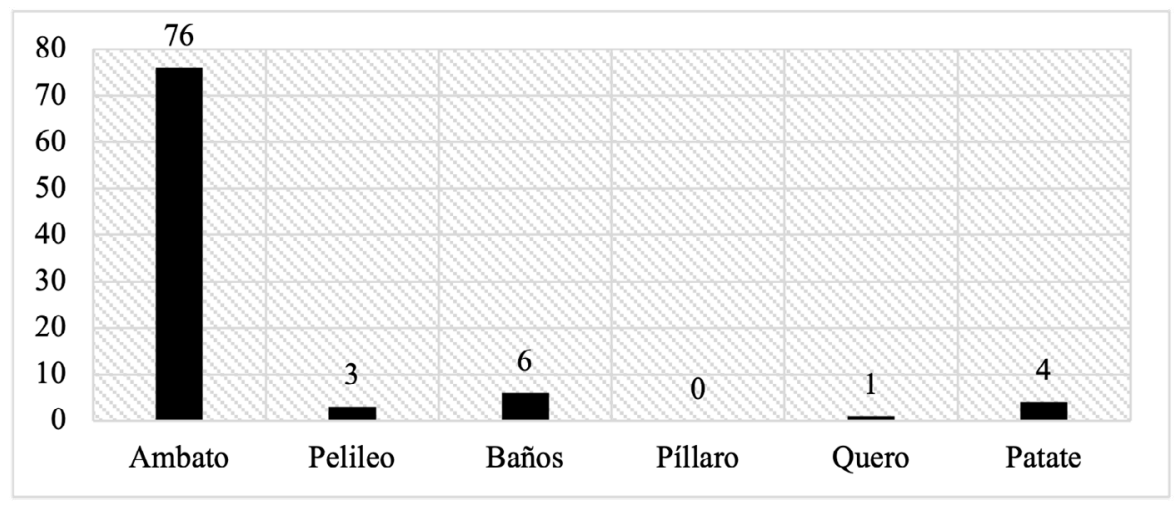

Fuente: Fiscalía General del Estado (2021)

El delito de acoso sexual, de acuerdo con la Figura 6, está presente en todos los cantones de la provincia de Tungurahua, a excepción de Santiago de Píllaro. El cantón Ambato presenta el mayor registro con setenta y seis casos, seguido de Baños de Agua Santa con seis delitos. Los cantones de San Pedro de Pelileo, Quero y Patate contabilizan tres, uno y cuatro delitos respectivamente. En el año 2018 es donde se evidencia un número considerado de estos delitos contra la libertad sexual con treinta y cuatro denuncias. 
Figura 7.

Abuso sexual

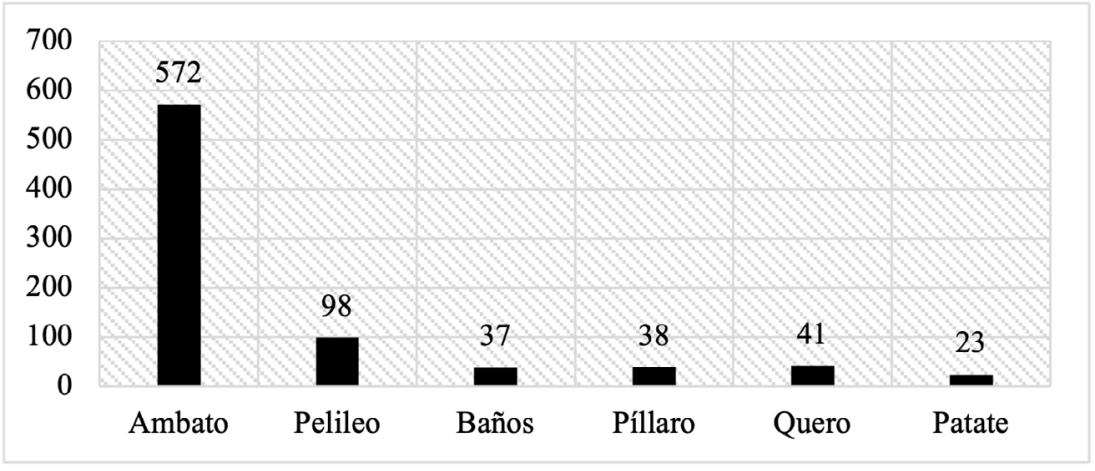

Fuente: Fiscalía General del Estado (2021)

En la provincia de Tungurahua, el delito de abuso sexual presenta la mayor tasa de incidencia con ochocientas nueve denuncias. Ambato es el cantón en donde se manifiesta este delito en contra de la libertad sexual con quinientos setenta y dos casos (Figura 7). De igual manera, existen noventa y ocho denuncias en San Pedro de Pelileo, convirtiéndose en el segundo cantón con mayor incidencia para el cometimiento de estos delitos. Quero es el tercer cantón con cuarenta y un denuncias. En el año 2019 se presentan en gran medida actos de abuso sexual con dos cientos cincuenta y nueve casos.

Figura 8.

Violación

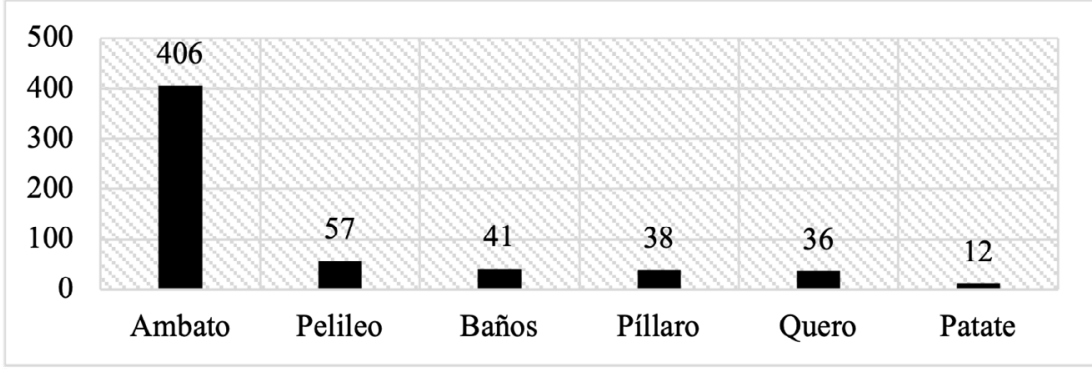

Fuente: Fiscalía General del Estado (2021)

Los casos de violación reportados en la provincia de Tungurahua son muy preocupantes, por cuanto las estadísticas revelan cifras considerables en todos los cantones. Ambato representa el cantón de mayor consideración con cuatrocientos seis reportes, como se puede ver en la Figura 8, seguido de Pelileo con cincuenta y siete denuncias. Baños es el tercer cantón con cuarenta y un registros de delitos. En toda la provincia se registran quinientos noventa casos, siendo el año 2019 el de mayor repunte con ciento setenta y tres delitos de éste género. 
Figura 9.

Utilización de personas para exhibición pública con fines de naturaleza sexual

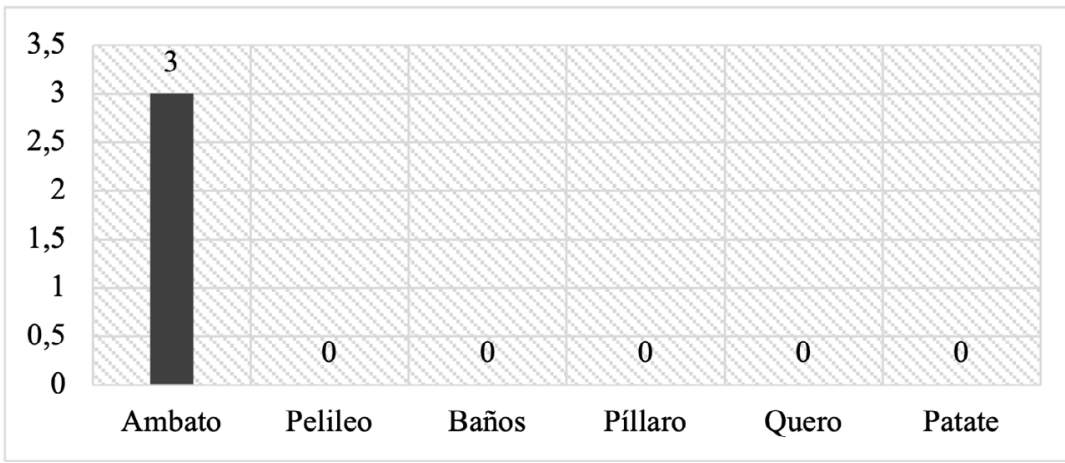

Fuente: Fiscalía General del Estado (2021)

Nuevos delitos que atentan contra la libertad sexual se están proliferando, como es el caso de la utilización de personas para exhibición pública con fines de naturaleza sexual que se contempla en el artículo 172 del Código Orgánico Integral Penal. Se registran tres casos en Ambato (Figura 9), con un caso en el año 2018 y dos denuncias en el 2019, los mismos que se encuentran en etapa de investigación previa.

Figura 10.

Contacto con finalidad sexual con menores de dieciocho años por medios electrónicos

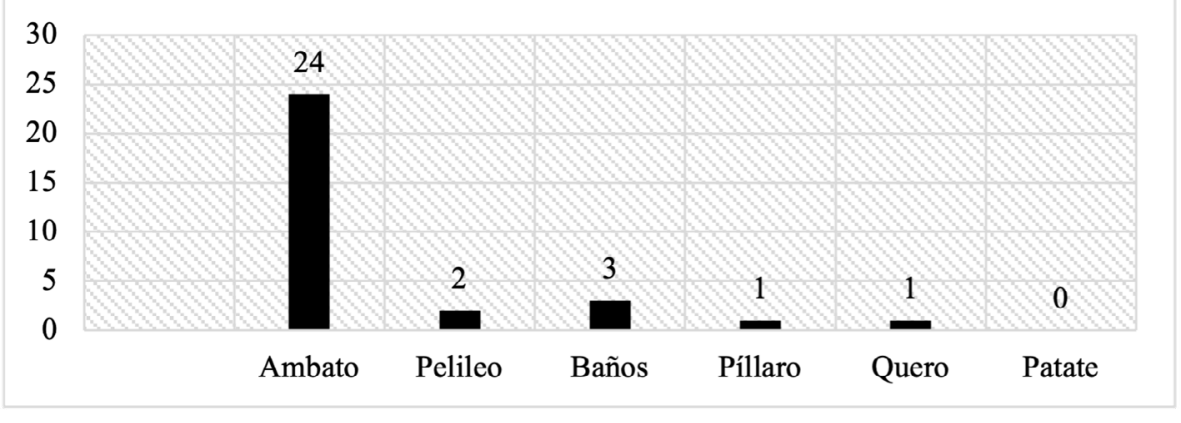

Fuente: Fiscalía General del Estado (2021)

Los medios electrónicos constituyen formas para el cometimiento de los delitos de contacto con finalidad sexual con menores de dieciocho años. Se contabilizan veinte y cuatro reportes en el cantón Ambato, como se observa en la Figura 10. El resto de cantones registran uno y dos casos. En Baños de Agua Santa se presentan tres delitos, en el 2021 existe una tendencia a aumentar estos delitos con once denuncias, de acuerdo al sistema integrado de actuaciones fiscales. 
Figura 11.

Contacto con finalidad sexual con menores de dieciocho años por medios electrónicos

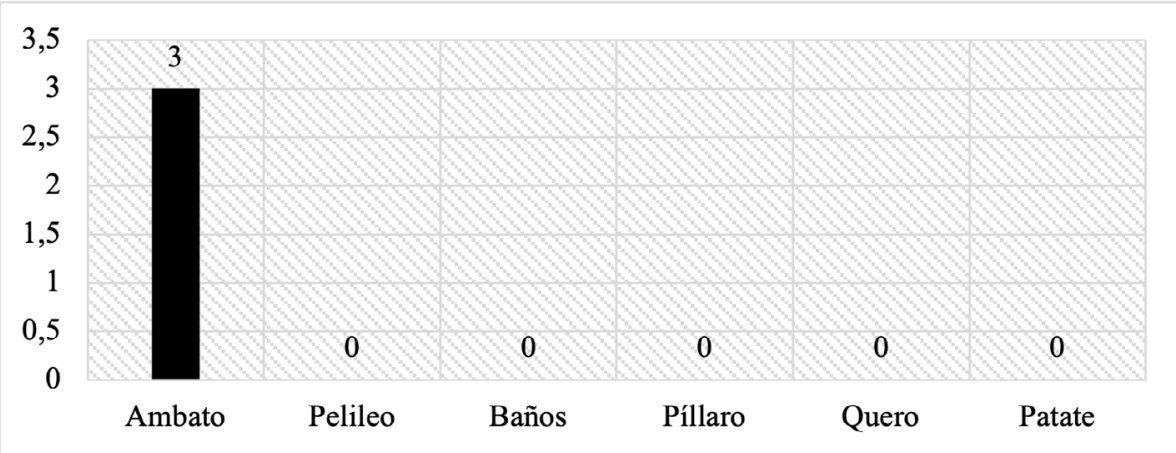

Fuente: Fiscalía General del Estado (2021)

El delito de oferta de servicios sexuales con menores de dieciocho años por medios electrónicos contemplado en el artículo 174 del Código Orgánico Integral Penal, se registra también en el cantón Ambato con tres casos en el año 2019 (Figura 11). Pelileo, Baños, Píllaro, Quero y Patate no presentan estadísticas relacionadas a estos delitos contra la libertad sexual.

Figura 12.

Delitos contra la libertad sexual por cantones

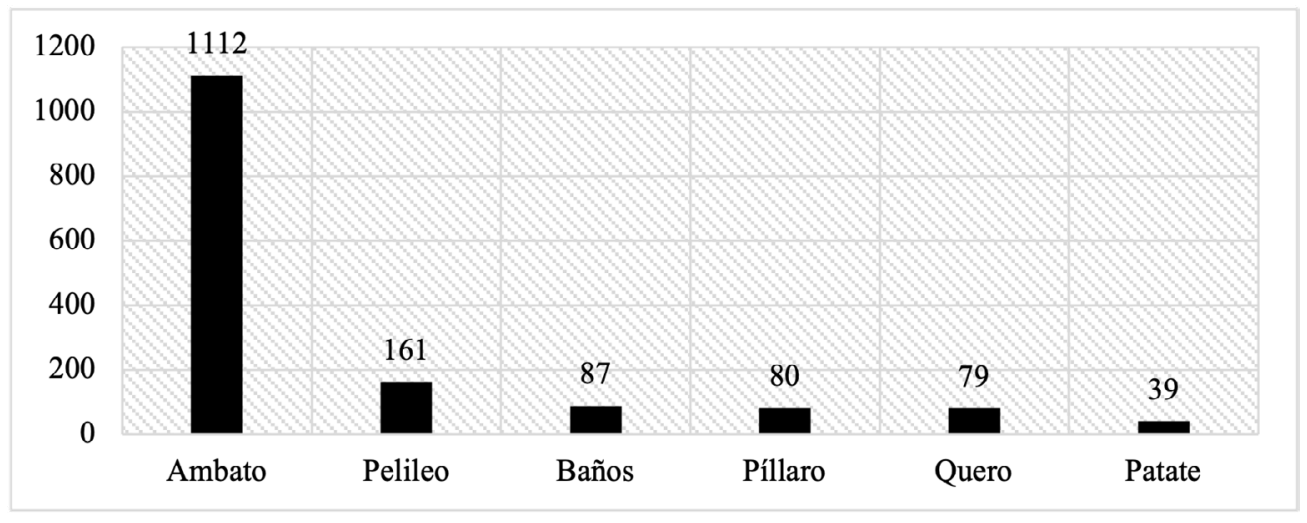

Fuente: Fiscalía General del Estado (2021)

El sistema integrado de actuaciones fiscales de la Fiscalía General del Estado registra un total de unas mil quinientas cincuenta y ocho denuncias de delitos contra la libertad sexual, siendo el cantón Ambato el más afectado con unos mil ciento doce casos (Figura 12). De igual manera, en el resto de cantones se han producido diferentes tipos de delitos. En Pelilelo se contabiliza ciento sesenta y un casos. Baños de Agua Santa constituye el tercer cantón afectado con ochenta y siete delitos en la provincia de Tungurahua. 
Figura 13.

Delitos contra la libertad sexual por años

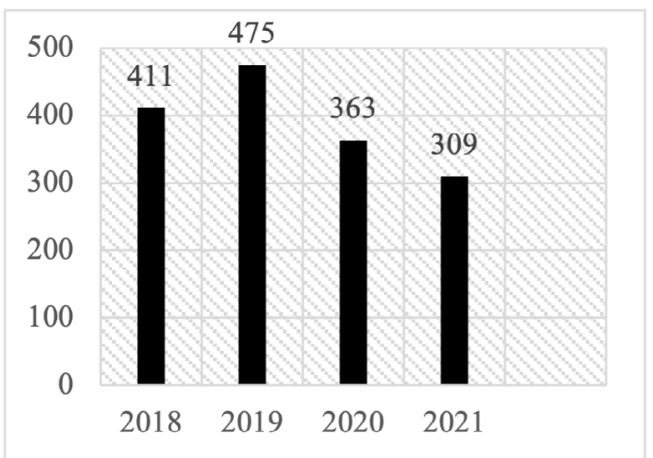

Fuente: Fiscalía General del Estado (2021)

Como se puede ver en la Figura 13, en el año 2019 se reportan la mayor cantidad de denuncias de delitos contra la libertad sexual con cuatrocientas setenta y cinco denuncias. En el 2018 se contabilizan cuatrocientos once casos. Para el año 2020 se totalizan tres cientos sesenta y tres delitos. Hasta el primero de agosto del 2021 se han generado tres cientos nueve denuncias de diferente clase de delitos contra la libertad sexual en los diferentes cantones de la provincia de Tungurahua. De acuerdo al estado procesal, la mayoría de delitos se encuentran en investigación previa.

Figura 14.

Explotación sexual de personas incluida la prostitución forzada, el turismo sexual y la pornografía infantil

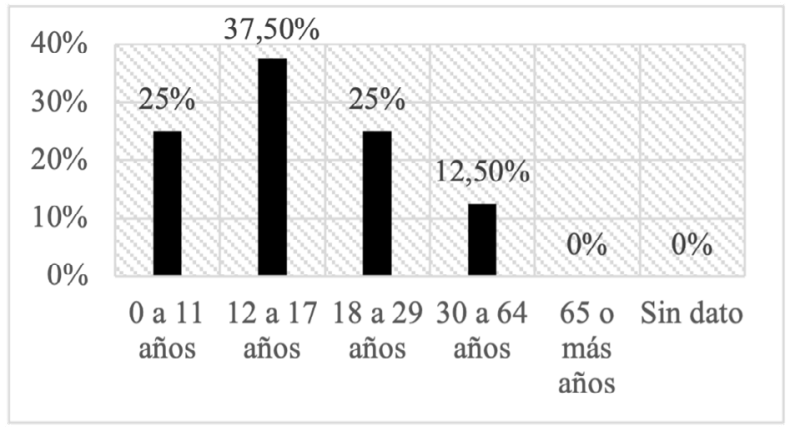

Fuente: Ministerio de Gobierno (2021)

El grupo etario comprendido entre los doce a los diez y siete años, presenta los mayores registros en el delito de explotación sexual de personas incluida la prostitución forzada, el turismo sexual y la pornografía infantil con el 37,50\% (Figura 14). De igual manera, los rangos de edades de cero a once años; y, diez y ocho a veinte y nueve años, tienen una estadística alta con el $25 \%$ de explotación sexual desde enero del 2018 hasta diciembre del 2021. 


\section{Conclusiones}

Como resultado de la presente investigación se puede evidenciar que se presentan en la provincia de Tungurahua varios casos de violación a menores, siendo víctimas de agresión doméstica, maltratos físicos, psicológicos y sexuales, constituyéndose en el grupo más vulnerable en la sociedad tungurahuense y ecuatoriana.

La Constitución de la República del Ecuador contempla garantías relacionadas con el respeto de los derechos para los llamados grupos de atención prioritaria que dada su situación de vulnerabilidad constituyen el sector poblacional más débil, $y$, por ende, susceptible de los delitos contra la libertad sexual, quienes son merecedores de atención preferente en los ámbitos público y privado.

Los delitos contra la libertad sexual en Ecuador han proliferado a través de las redes sociales y medios electrónicos, de ahí que el Código Orgánico Integral Penal ha incluido nuevos tipos de delitos contra la libertad sexual y reproductiva como la distribución de material pornográfico a niñas, niños y adolescentes, la corrupción de niñas, niños y adolescentes, la utilización de personas para exhibición pública con fines de naturaleza sexual, el contacto con finalidad sexual con menores de dieciocho años por medios electrónicos, la oferta de servicios sexuales con menores de dieciocho años por medios electrónicos, entre otros.

Por su parte, el Código de la Niñez y Adolescencia incorpora en su texto normas encaminadas a la protección integral de la niñez y adolescencia, estableciendo responsabilidades para el Estado, la sociedad y la familia, en la lucha por conseguir su desarrollo integral; pondera el respeto del principio de interés superior; pero también los deberes que este grupo poblacional debe cumplir, adicional de los medios necesarios para el goce efectivo de estos derechos.

Los delitos contra la libertad sexual tienen ocurrencia y son perpetrados en su mayoría por los mismos progenitores, parientes y amigos que están en contacto con el entorno familiar de la víctima; sin embargo, gran parte de casos de delitos sexuales no son denunciados por cuanto la persona perjudicada decide guardar silencio por miedo a ser revictimizada por el agresor.

En el cantón Ambato los casos de acoso sexual, abuso sexual y violaciones constituyen los delitos contra la libertad sexual más representativos con estadísticas de denuncias muy altas, en relación al resto de cantones. Los nuevos delitos que se producen por medios electrónicos están proliferando de manera significativa, siendo el contacto con finalidad sexual con menores de dieciocho años, el delito que registra más casos en la provincia de Tungurahua, según datos de la Fiscalía General del Estado, durante el período analizado del 2018 al 2021. 


\section{Referencias}

Asamblea Nacional del Ecuador. Código de la Niñez y Adolescencia. (2014). Registro Oficial 737. Última modificación. https://www.igualdad.gob.ec/wp-content/uploads/downloads/2017/11/codigo ninezyadolescencia. pdf

Asamblea Nacional del Ecuador. (2021). Código Orgánico Integral Penal. Registro Oficial Suplemento 180. Última modificación https://www.defensa.gob.ec/wp-content/uploads/downloads/2021/03/COIP act feb2021.pdf

Asamblea Nacional del Ecuador. (2008). Constitución de la República del Ecuador. https://www.asambleanacional.gob.ec/sites/default/files/documents/old/constitucion de bolsillo.pdf

De Urabá, C. (23 de octubre de 2021). La revelada violencia sexual en tiempos de la Conquista. Las2Orillas. https://www.las2orillas.co/la-revelada-violencia-sexual-en-tiempos-de-la-conquista/

El Universo. (03 de enero de 2021). 6 de cada 10 delitos sexuales se cometen en casa, por los familiares de las víctimas. https://www.eluniverso.com/noticias/2020/12/14/nota/8107966/6-cada-10-delitos-sexuales-se-cometen-casas/

Ernst, M. (2007). Los delitos contra la libertad sexual en el Ecuador. Un análisis desde la experiencia. Revista Aportes Andinos: revista de derechos humanos, (18). Universidad Andina Simón Bolívar. http://hdl.handle. $\underline{\text { net/10644/867 }}$

Estrella, E. (2019). Análisis de la no revictimización de víctimas de delitos sexuales, por los operadores de justicia en el Ecuador (causa IP 124). [Tesis de grado, Universidad de Guayaquil] Repositorio Universidad de Guayaquil. http://repositorio.ug.edu.ec/handle/redug/43133

Fiscalía General del Estado. (2021). Dirección de Estadística y Sistemas de Información.

Fiscalía General del Estado. (2021). Sistema Integrado de Actuaciones Fiscales.

Instituto Nacional de Estadística y Censos. (2019). Violencia de Género. Encuesta nacional sobre relaciones familiares y violencia de género contra las mujeres. INEC. https://www.ecuadorencifras.gob.ec//violencia-de-genero/

La Hora. (03 de septiembre de 2017). Denuncias por delitos sexuales incrementaron en la Fiscalía de Tungurahua. https://lahora.com.ec/tungurahua/noticia/1102097135/denuncias-por-delitos-sexuales-incrementaron-en-la-fiscalia-de-tungurahua

Martínez, G. (2015). Aproximación histórica a los abusos sexuales a menores. Eguzkilore, (2), 137-170. https:// www.ehu.eus/documents/1736829/5274977/07+Saez 
Mejía-Rodríguez, U., Bolaños-Cardozo, J., \& Mejía-Rodríguez, M. (2015). Delitos contra la libertad sexual. Acta Médica Peruana, 32(3) 169-172. http://www.scielo.org.pe/scielo.php?script=sci arttext\&pi$\mathrm{d}=\mathbf{S} 1728-59172015000300007$

Ministerio de Educación. (2011). Prevención y abordaje inicial de los delitos contra la libertad sexual en el ámbito educativo. Coordinación General de Administración Escolar.

Ministerio de Gobierno. (2021). Mapa interactivo de los delitos de trata de personas y tráfico ilícito de migrantes en Ecuador. Dirección de Prevención de Trata de Personas y Tráfico de Migrantes. http://www.trataytrafico.gob.ec/estadisticas/mapaecuador

Ortiz, M. A. (2020). La víctima en los delitos contra la integridad sexual. Universidad y Sociedad, 12(3), $353-363$. http://scielo.sld.cu/scielo.php?script=sci_arttext\&pid=S2218-36202020000300353

Tafur, L., Giraldo, E., \& Camelo, I. (2019). Identificación de las causas y los efectos del delito de abuso sexual en niños, niñas y adolescentes en el municipio de Lérida - Tolima. [Tesis de grado, Universidad Cooperativa de Colombia]. 
Copyright (c) 2022 Vicente Leonardo Pérez Yauli, Jorge Oswaldo Tamayo Viera e Ibeth Aracelly Molina Arcos

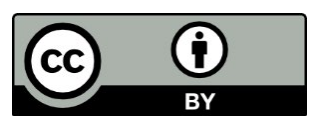

Este texto está protegido bajo una licencia internacional Creative Commons 4.0.

Usted es libre para Compartir-copiar y redistribuir el material en cualquier medio o formato

- y Adaptar el documento - remezclar, transformar y crear a partir del material-para cualquier propósito, incluso para fines comerciales, siempre que cumpla las condiciones de Atribución. Usted debe dar crédito a la obra original de manera adecuada, proporcionar un enlace a la licencia, e indicar si se han realizado cambios. Puede hacerlo en cualquier forma razonable, pero no de forma tal que sugiera que tiene el apoyo del licenciante o lo recibe por el uso que hace de la obra.

\section{$\underline{\text { Resumen de licencia - Texto completo de la licencia }}$}

